\title{
A trip to Riviera Maya, Tulum, Sankan Researve Forest, Quinta Roo and Chichenitza, Yucanta: Regions of Mega Biodiversity and Antique Maya culture
}

\author{
Ratikanta Maiti* and Sandip Maiti
}

Av. del museo 1118, Valle de los Flores, san nicolas de los Garza, cp 66438, Nuevoleon, Mexico

\section{Article History}

Manuscript No. AR1079a

Received in $14^{\text {th }}$ November, 2014

Received in revised form $23^{\text {rd }}$ November, 2014

Accepted in final form $4^{\text {th }}$ December, 2014

\section{Correspondence to}

*E-mail: ratikanta.maiti@gmail.com

\begin{abstract}
We made a joyous and educational trip from 26 June to $6^{\text {th }}$ July, 2014 to Riviera Maya, Tulum, Sian Ka'an Reserve forest, Punta de Allen, Qintanaroo and Chichen Itza, Yucatan, Sothern regions of Mexico. The enchanting nature the beauty and biodiversity of plants and wild animals remain a reflection of ancient Mayan Culture. We got down from our two hour flight from Monterrey to Cancun and started a long but enjoyable trip through great diversity of trees and shrubs in tropical rainforests in the tourist van before we arrived at our hotel.
\end{abstract}

\section{Keywords}

Trip, mega biodiversity, antique maya culture, Mexico

Mexico is considered a country of megadiversity for its richness in flora and fauna. Though we did not have opportunity to take quantitative data we could observe visually the diversity in flora and fauna on both sides of roads. I could note the diversity in shrubs, trees in terms of their heights, crown and leaf canopy architecture, and the leaves varying in size, shapes, pigment content, each species occupying its niche growing luxuriantly and in harmony to capture solar radiation for photosynthesis, without any competition in the above ground shoot system and most probably in the underground soil profile with root system growing to different depths to absorb nutrients and water for its growth. Most of the species have open canopy leaves, generally highly branched. In this ecosystem, the climbers seem to climb up to the upper part of crown without affecting much the growth of its host tree; this is the mode of adaptation in the forest ecosystem both in the rainforests as well as in thorn scrub of semiarid regions of Mexico.

Rivieria Maya is situated along Mexico's northern coastline on the bank of turquoise waters of the Caribbean Maya Riviera; along $120 \mathrm{~km}$ of soft sandy beach of Carribean, occasionally turbulent seas. This region of high biodiversity possesses green rainforests, ancient wells, several archaeological sites, natural undisturbed reserve forests, beautiful parks, picturesque native villages and many other tourist attractions. This region is rich in history and old traditions and experience a fascinating adventure associated with enchanting natural surroundings and charming birds. All these natural surroundings represent a fundamental part of life on the Maya Riviera.

We stayed for 5 days in Blue Bay Grand Esmeralda Hotel situated in the midst of tropical rainforest, tall mangrove forests with wild animals moving all around. The forests and the ecosystem seem well conserved by the hotel administration. The tourists could enjoy the beauty of the silent evergreen mangrove forests.

This area possesses two vitally important ecosystems; the mangrove swamps and the rainforest. The mangrove swamps are made up of groups of trees which owing to their physiological characteristics are able to survive and reach maturity on flooded land. These swamps are associated with coastal areas, streams, rivers and lagoons. Three types of Caribbean species of mangrove are found in the region: the red mangrove, black mangrove, white mangrove. Soft wood mangroves are a vital resource for their high productivity of organic matter. These mangrove swamps serve as a breeding ground for a large diversity of fish, crustaceans and larger land-dwelling wild animals as well as marine species. The 
mangroves are particularly important for high release of oxygen and often provide protection against storms and hurricanes.

The other outstanding ecosystem is the rainforest, which is characterized by the abundance and leafiness of the tall trees, palms and exotic flowers. They are shelter for many animals such as: deer, badgers, anteaters, grisons, squirrels, iguanas, eagles, paca and possums.

Mangrove plants are very tall (approx 50-60 m), stems thin, leaf canopy open, leaves are lanceolate to broad and thick deep green with shining waxy coating to prevent loss of water by transpiration. The stems are unbranched with rudimentary lateral branch at the upper part of stems bearing leaves which help in the photosynthesis required for the elongation and the growth of the stem. Although having thin stems the neighbouring plants give support not to bend, thereby, maintain a harmony with their neighbours. The topmost part of the plant is branched giving an irregular contour. Fleshy porous rhizophores arising from upper branch grow downwards and fix the tips on the soil and thereby support the upper branch. Numerous rhizophores are fixed on the ground so extensively as if protecting their domain from trespassers. All the leaves starting from the upper branches to the lower ones receive light owing to the horizontal orientation of leaves for photosynthesis and continuous elongation and growth of the plants.

One has to acknowledge the mechanism of adaptation of mangrove plants that grow luxuriantly tall in the highly saline soils. We do not observe any sign of salinity stress in their growth habit. Roots help only to fix the plants, but do not absorb water. The fleshy rhizophores possess pneumatophore through which they absorb water vapour and undertake respiratory functions. Besides the leaves have xerophytic characteristics, with thick leaves having waxy shining coating to avoid loss of water by transpiration. In addition in our study, it is observed that Mangrove leaves possess compact palisade cells to check loss of water through stomata.

While there are a number of trees that tolerate some soil salinity and salt over-spray, there is just one species, the mangrove that actually grows submerged in salt water for much of its life. The mangrove is specifically adapted not only to survive the dehydrating effects of salt, but to thrive and spread. Trees besides the mangrove that have high tolerance for salinity include, but are not limited to, horse chestnut, ash, honey locust, sycamore and hedge maples, sweet gum and American holly. Mangroves are able to filter out some salt at root level and some through its leaves, mangrove is also able to tolerate a much higher internal level of salinity. Its sap may be up to 10 percent as salty as seawater. They are also able to breathe, absorbing oxygen through pore-like lenticels on their above-ground roots. This allows them to thrive in anaerobic soil, where there is a lack of oxygen. Their aerial roots which, while above-ground, spend part of their time submerged by high tide not only absorb oxygen, but are also able to transport it throughout the rest of the tree. Even though the mangrove can tolerate salinity, it also relies on freshwater to flush excess salt out of its system. Without freshwater flushing, the trees would die. Rain provides the freshwater needed for their survival.

\section{Red Mangrove}

With the most exposure to saltwater, the red mangrove grows off tropical coastlines as well as off the coast of Florida. It is an important player in the local ecosystem, providing food and shelter for many sea animals, as well as preventing erosion of the coastline. In tropical regions, it may reach 80 feet in height, but Florida's mangrove is a shrubby tree that barely reaches 20 feet. It flowers in the spring, and produces seeds that germinate while still on the mother tree, sending a root out from the seed base. Once it falls, it lodges and begins growing as soon as it contacts soil.

\section{White Mangrove}

White mangroves appear not only along coastlines but also grow in lagoons, and can be somewhat larger than the red versions. They are unique in that they produce small glands at the base of the leaf that emit sugary nectar. A variety of insects and birds feed on the nectar. The prop roots of these trees arc out of the water and provide oxygen at high tide, and may originate from either the trunk of the tree or the branches. The roots of the tree help to build "islands" by trapping sand and sediment, allowing it to form a landing for additional trees to root.

\section{Black Mangrove}

Growing inland in low-lying coastal areas, the black mangrove is only exposed to saltwater during the highest of tides. It grows along coastal estuaries, and holds off erosion of coastal land. The black, hard wood of the tree has been used in building and carpentry, and the tannins in its leaves are often utilized for preparing leather hide. Beekeepers prize the nectar of the white flower for honey production, as it yields high-quality honey. Black mangrove breathes through tubelike pnuematophores rather than prop roots. Its 50 -foot height decreases the farther north the tree grows (Source, Southwest Florida Water Management District: Wetland Connection Marietta College: Wetland Habitat Tour).

I observed that light penetrates vertically through open canopy leaves and reach to the ground. The flowers are large sized and brilliant White in color. It is observed the flowers start blooming at night (about $10 \mathrm{pm}$ ) up to next day in the afternoon but are found to fall in the evening time which means the plant has to complete fertilization during that period. 

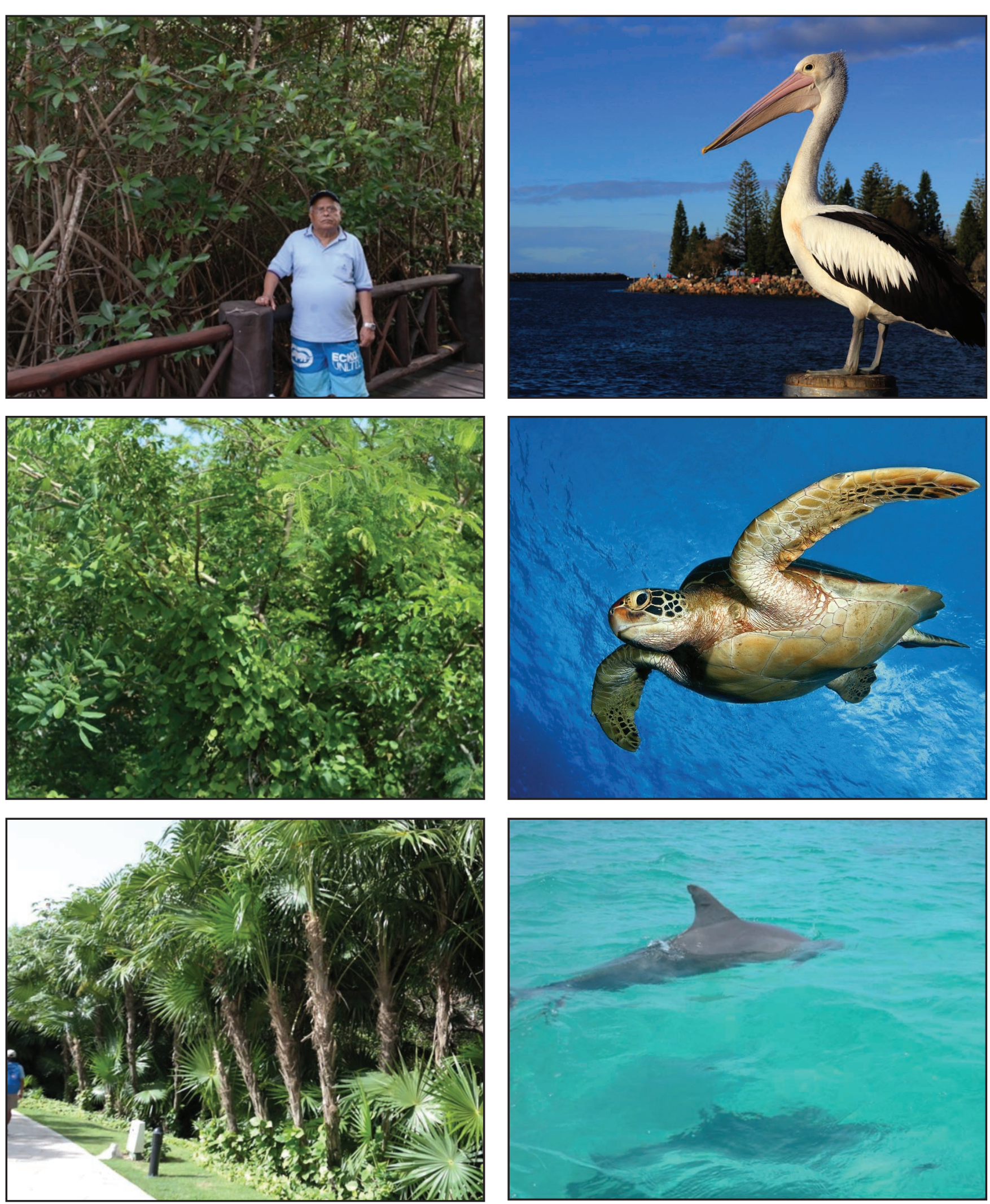

Mega Biodiversity in a trip to Riviera Maya, Tulum, Sankan Researve Forest, Quinta Roo and Chichenitza, Yucanta 

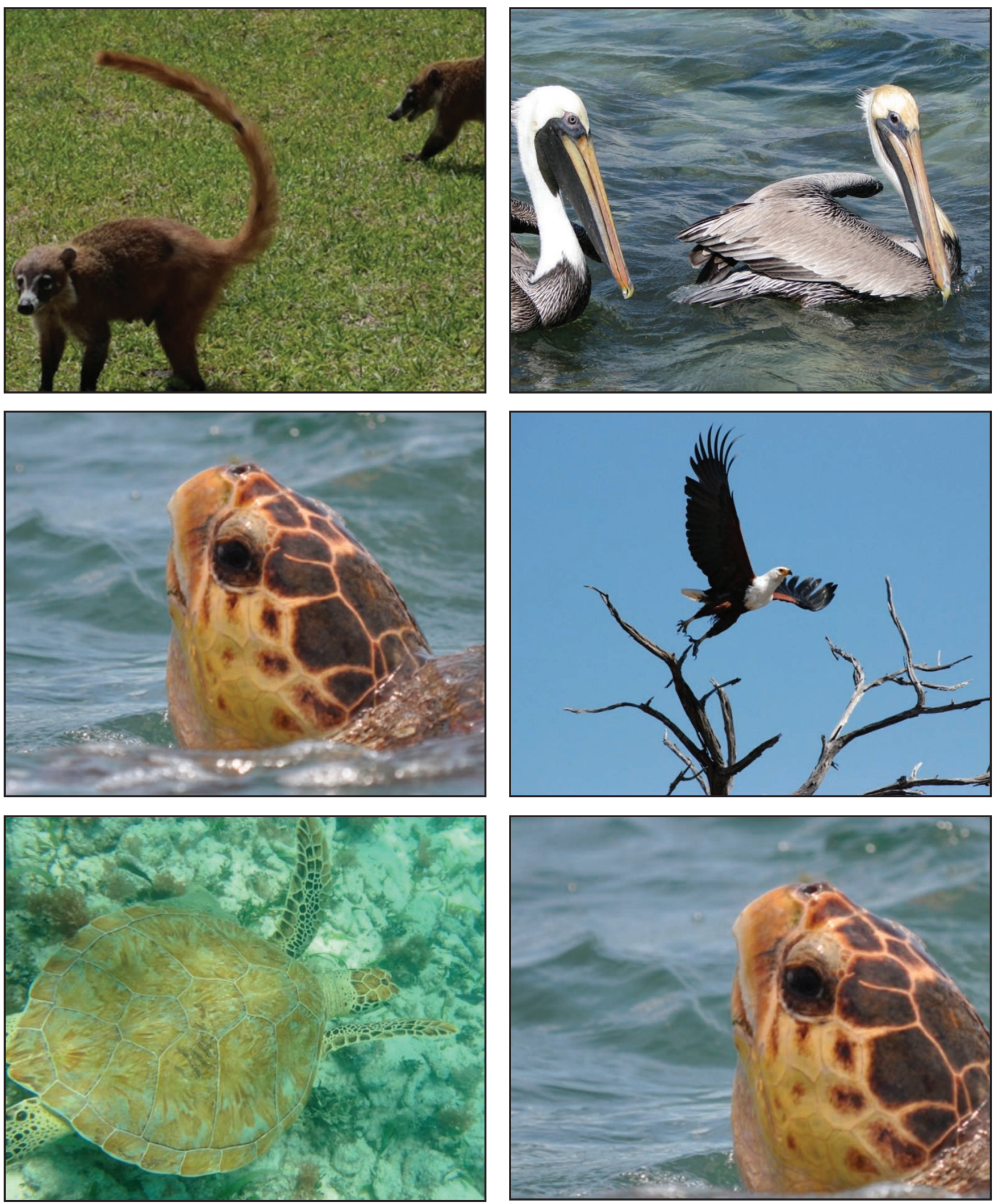

Mega Biodiversity in a trip to Riviera Maya, Tulum, Sankan Researve Forest, Quinta Roo and Chichenitza, Yucanta 
The Blue Bay Grand Esmeralda has adopted the following strategy to conserved these ecosystems?

- It regulates the drainage of water and also conserve the water system, acting as a biological corridor for fauna.

- They use biodegradable chemical products in the different areas of the hotel thereby avoiding damage to the environment.

- The products supplied to us fulfil environmental regulations.

- They use a biological system at the sewage treatment plant and re-use the water from this in the watering system in order to make the most of this resource.

- Ecological walks for children are organized, to inspire and develop the instinct to appreciate and protect nature.

- In the hotel rooms an energy-saving system where magnetic switches are used to automatically cut off power when the room is without an occupant with the sensors in the sliding doors automatically turning off air-conditioning.

A trip to Tulum, Reserve forests of Sian ka'an finally reaching sea beach of Carribean sea at Punta de Allen.

In order to reach the sea coast at Punta de Allen we travelled in tourist van through corrugated and zigzag narrow stony roads passing through dense forests of Reserve Biosphere of Sian ka'an. This is extended over $15,710000 \mathrm{ha} /$. This is rich in vegetation with diversity of flora and fauna. There exists large variability in crown and leaf canopy structure. Most of these trees have open leaf canopy with highly branched thin stems, some with close canopy possess stout main trunk with thick primary stems. Each species has characteristic crown occupying its niche without disturbing its neighbour. Some are very tall, medium in height and some short thereby occupying the available spaces and sharing solar radiation for photosynthesis. Climbers grow over the crown thereby competing with the host for sharing sunlight. Several species of palms are dominant near the road sides. The palm leaves are used for house thatching which last for more than ten years. No electricity supply is available in the region. Artificial gas light or solar light is used for local electricity. On the way our guide showed us two dilapidated house of Mayas depicting the remnant of Maya culture. The guide showed us the gate of a Mayan house which is very low. One of the tourists could enter in but had difficulty coming out. It took us more than 2 and $1 / 2$ hours to reach our destination the Punta de Allen, the beach of Carribean sea.

All of us were tired and very hungry, They served us a light snack and soft drink. We got ready for journey over the sea in a launch. Each one of us has to wear life jacket. Six persons of our family boarded a big launch with a driver having 12 years of experience. The eternal Carribean sea with bluish turbulent water was a fascinating tour of three hours. The driver told us the sea was less turbulent that day compared to other days. We were really lucky. More than 12 launches are full of passengers. We are thrilled and not afraid at all at my age of 82 . The driver was of amicable personality and explained us the beauty of marine nature with its fauna and submerged flora, the marine algae which are the source of food for fish. He planned the tour so that we can see different fauna in the sea.

The sea seems to us shallow because we can see blue green algae from launch. My son Dr, Sandip and my grandson started taking photographs of the flying birds as well as the deep water algae and fish using aquatic camera. It was a thrilling journey with splash of sea water on our face and clothes. We were taken to different zones of marine animals and birds.

\section{Zones Tortoise}

First he took us to zones of tortoise, very big in size with coloured specks on the bony cover, some are more than 20 years. It was really amazing to watch them floating over the sea and diving deep, raising their mouth up for a breath. The driver told us they dive up and down in the sea for catching their prey. I felt very bad that the driver had to drive through tortoises disturbing their activities and also the marine biodiversity.

\section{Paradise of fish fauna, coral, and marine algae}

The launch pilot advised my son to push down aquatic camera deep to take photographs of varieties of fish fauna, coral and upgrowing bush of marine algae. Later I observe it looks like a paradise, a kingdom of of several varieties of fish of different colours and different sizes, red, black, some with beautiful ornamentation of white and black or red strips on the body scale swimming around and harbouring on algal flora, coral which they eat. They live together as symbionts forming an ecosystem of fauna and algal flora, beautifully orchestrated. The algal flora looks like a flower garden of different colours, deep yellow, green, blue green, red looking like globes with bunch of ribbon like filament, some look like a bunch of red fruits. The algae of different showy colour attract the fish as if inviting them to feed them. Both fish fauna and algal flora live in harmony. Probably they belong to Pheophyta, Rhodophyata, Cyanophyta containing yellow xanthophyll, carotenoids. Corals, a group of invertebrates are of different colours, red, white, black and yellow. I had the intention to collect these algae for identification but could not as it is was strictly prohibited, it being a biosphere reserve, a UNESCO site and Ramsar Site. We should respect and conserve this valuable marine biodiversity. These algae containing different pigments have capacity to undergo photosynthesis and produce different types of photosynthates such as fucoxanthin, fucoerythrin, phaeophytin unlike carbohydrate, necessary for their growth. It felt like a tranquil paradise, taking me far away from the 
stressful outside world. We need to conserve this nature's gift. We should conserve them carefully and maintain the marine biodiversity

Journey through mangroves and regions of crocodiles near sea beaches: territory of crocodiles

After visiting and enjoying the territory of tortoise and biodiversity of underground algal and fish fauna, we drove through silent lakes in the mangrove forests to the zones of crocodiles and birds. We tried to look for crocodiles but unfortunately we could not locate them during our journey time they were probably taking rest under some mangrove trees in between rhizophore. I could appreciate the ecosystem of mangroves on the banks though I could not identify the species as the launch was moving at a high speed. The plants are highly branched with thick lanceolate leaves with open canopy for the capture of carbon through photosynthesis. The most interesting feature, I could observe the way the mangroves protect soil erosion by their strong horizontally ramifying rhizophores. During low tide the rhizophores absorb water vapour from the sea necessary for photosynthesis and plant metabolism as well as oxygen for respiration. The plants are healthy in the highly saline aquatic environment and did not show signs of symptoms for salinity stress. Being a Botanist I did not have any chance to observe the mechanism of adaptation of mangroves at the extreme saline environment. We could observe several birds on the branches of the trees, some enjoying fish in their beaks recently captured from the sea. We could watch a number of wild marine ducks, turkey, pelicans observing us while we were driving through the sea. They do not feel disturbed by the horrible sounds of the launch probably used to visitors regularly. They seem happy in their territory.

Visit to territory of Dolphins: Play ground of Dolphins

After visiting the zone of mangrove forests near the sea shore, our launch driver took us to the territory of gigantic dolphins. He asked my son to get ready with camera including aquatic camera. We saw the huge dolphins, may be more than 500 $\mathrm{kg}$ jumping over the sea water and diving down for catching their prey around the algal and coral colony. It is afternoon, the time of food. With aquatic camera my grandson took nice photographs of dolphins diving through tidal water, jumping up and down. They are playing like games and at the same time catching fish and gulping them voraciously. Our driver drove behind them to give us an opportunity to see and take good photographs, I was really afraid cautioning the driver not to collide and hurt them. A series of launch were behind us looking for dolphins. We are really causing damage to the diversity of dolphins in their territory. Though the authority asked them not to disturb these precious creatures some wanted to please the tourists, driving and running behind the dolphins and disturbing them. They were really hungry and busy to catch their prey. Thanks to my son who motivated us to take this tour I had the opportunity to see and enjoy the view of gigantic dolphins in my life. We human beings are selfish and disturb the territory of these precious marine creatures for our personal satisfaction. We were really happy and will never forget the games of dolphins jumping up and down.

\section{Zones of pelicans and sea ducks}

After an enjoyable visit in the territory of dolphin the guide took us to zone of pelicans with big coloured beaks sitting on the mango trees looking at us without being disturbed by the roaring launch. This is really enjoyable scene, the gift of nature,

\section{Zones of sea dives and swimming}

Finally the guide took us to a silent zone with shallow water and asked the tourists to jump down for a swim. It is a beautiful scene. Many of them float on the sea water with their life jackets. My son, daughter-in-law, granddaughter and grandson got down and enjoyed swimming in the silent water for about 30 minute. We could not get down for our old age.

\section{Return to the boarding zone}

Finally we arrived to the boarding zone. The guide asked us to take food served as buffet. We were very much hungry and took the food eagerly.

\section{Return journey through Sian ka'an Reserve Forest}

The guide asked us to board the van for a return journey to our hotel. About 20 vans started through deep forests over the rugged road. The condition of roads was very bad and the old van was no help either breaking down several times on the way. It was a horrible journey and I felt the government should repair the roads for the comfort and safety of the tourists.

The hotel authority made good arrangement for our breakfast, lunch and dinner in a restaurant about one kilometre from our hotel. They made arrangement for transport in a small train. Sometimes we used to walk through mangrove forests watching on both sides of the roads the hanging rhizophores, palm trees, mangrove flowers, animals scuttling off, a rare deer, lizzards, etc.

Sufficient food of various types was served as buffet. We really enjoyed delicious food,

At 9 pm we enjoyed Mexican traditional songs and dances in a big gathering. Many foreigners from different countries could really enjoy the traditional songs, and dances typical of different states. All enjoyed and clapped.

\section{Visit to Hichen Itza, Merida, The Yucatan}

We booked van for a trip to Chichen Itza, the historical pyramid 
of Maya culture located in Merida far south in the Yucatan, Southern Mexico.

We started our journey early in the morning again through tropical rainforest on both side of the road. I was enjoying the biodiversity of the rainforests and its ecosystem. The forest is dense consisting of shrubs, trees, climbers. As our vehicle moving very fast, it was difficult for me to identify the type of vegetation. I could observe, most of the tree species have open leaf canopy with highly branched thin stems which favour efficient capture of light and translocation of photosynthates in stems and other plant parts. They grow in height compared to those with close canopy leaves. Some species possess close leaf canopy which have short stout stem with large basal diameter with few primary branches with thicker stems. There are large variations in leaf morphology, size, shape, surface structure, intensity of leaf pigments.

On the basis of my analysis of the rainforest of both Riviera Maya, Sian ka'an Reserve Biosphere and that of Yucatan we can classify plants in two distinct types,

\section{Open leaf canopy}

In this category, the woody species possess open leaf canopy giving an opportunity for the capture of sunlight efficiently for photosynthesis. They may possess either lanceolate narrow, serrated leaves or broad big or small leaves The distinct characteristics of these species, they possess the highly branched stems with thinner stems.

\section{Close leaf canopy}

These species possess very close leaf canopy with overlapping lower leaves which receive less light for photosynthesis. Too many crowded leaves represent the wastage of solar energy and organic matter. These species possess short thick basal stem which may be bi- or trifurcated to produce thick primary stem. These species may possess either narrow or broad big or small leaves as in the case of first category. The leaves on the upper crown and lateral sides of the plant only can capture solar radiation for photosynthesis and the photosynthates are translocated to the basal stem and primary stems and other plant parts.

\section{Intermediate category}

With a decrease in leaf canopy the branching of stems reduce and the basal stem diameter increase.

\section{Visit to Water Table River Well called Cenote}

On the way to Chichen Itza, the guide, the van driver was explaining us the history of old Maya culture which was much advanced scientifically than other tribes like Aztecas, Olmecas in Mexico. They were strong in Mathematics and Astronomy; they did not use any letters like English, or Spanish. They used symbols/scripts only to communicate with each other. It is confirmed by the modern astronomists their predictions were perfect. The marriage system was also modern where the bridegroom lives with the girl before marriage. The father of the bride has to give fruits, vegetable, food grains and other things as gift to the girl at the time of marriage. During marriage they danced and drank wine the whole night. We were told that Mayas still live in their native village and maintain their traditional customs, dresses, and hunt wild animals for their food. The land is fertile, where they grow rice, sugarcane, vegetables and different types of fruits.

On the way he took a bypass path in rugged road in order to take us to underground river called: "CENOTE". The road was very bad. He explained that more than 7000 underground rivers are reported which ultimately flow to the sea. Only two or three are opened for the public. Ultimately we arrived at the famous cenote. There are more than 20 steps to go down to the underground river. Tourists who wanted to take bath in the river had to take a shower in a bathroom before entering the cenote to upkeep the hygiene of the river. I did not go down but my son went down to the river ridge with his family. I watched few tourists swimming happily. The water is bluish and clean, safe to drink. On the top there was a hut where the Mayas were selling their handicrafts, goddesses they worship for different purposes showing the cultural similarity with the Hindu religion. My son purchased idols of gods which the Mayas worship in their native villages still down, I asked my son to take photograph with a Maya who was selling the handicrafts in a community shop shared by village society. They are fair in complexion and the Mayan women were beautiful. We are told that though Spaniards married Mayas, thereby leading to mixed culture but in the native village marriage is restricted only with native Mayas who speak in their native languages. I developed respect for this culture.

The guide started journey on way to our final destination Chichen Itza. On the way he took us to a community restaurant for our lunch. Different types of food preparations were served as buffets. We had to wait for about 45 minutes in a queue to get opportunity to get space for sitting. We were hungry. We could relish food without complaint.

After lunch the guide took us to the historic place of the great pyramid Chichen Itza. It was a very hot day with scorching sun burning our forehead and arms. Both of us sat on a wooden bench under the shade of a big tree having close canopy. Just in front of us, the historical huge pyramids were standing as if inviting us to climb up. I visited this place earlier and remembered all places of interest. The pyramid has four sides with innumerable staircase to climb up. Last time we could climb up but now the tourism department has prohibited the 
tourists to climb up. The tourists are asked by the guides to clap hands which gave a musical sound of a bird from the topmost peak of the pyramid.

In 2007, the NASA scientists visited the pyramid and found that they can predict perfectly the astronomical positions, far better than the modern science. The Chichen Itza is now included as miracle of the world for its architecture, astronomical interest and scientific austerity. The guide was explaining to a group of tourists about the history of this gigantic pyramid which depicts early history of Maya culture. On a particular full moon night the tourists from all over the places and foreigners gather on the ground in front of the pyramid. They sing songs and pray to MOON to come down to the world. We are told by one of the tourists who was a witness, that The Moon comes down high from the sky and sits down on the topmost floor of the pyramid and all tourists clap hands and sing songs to please moon, an amazing experience indeed.

The pyramid is surrounded by typical ecosystems consisting of huge tree with close canopy, huge basal trunk with high basal diameter and widely spaced. Under the shade of the trees there are small shops selling handicrafts, typical of Maya culture. Some were selling trumpet which gives sounds of typical animal or birds of the region. The surroundings are flooded with tourists from all over the world,

The sacred pyramid represents the glory of Maya culture and advance in science. Though Spaniards have demolished and destroyed several building with scattered idols of Gods, animals of the regions, but the pyramid remains intact. They tried but failed to do any damage to this sacred building.

Being ignorant of the sanctity of the place I want to mention only few more things. Probably the rulers use $d$ to kill the victims by shooting them tied against the pillars. Very near to this building we saw a place where pillars are standing

On the left side we could see the destroyed building which was the sports arena for the Mayas. All the guides took the tourists on roads meandering between half destroyed buildings, sculpture of animals, birds, other creatures of the region. In one place they showed us piles of stones imitating maize cobs which represent symbols of fertility.

Finally they took all the tourists to a famous sacred well. It has spiritual history. It was told that the devotees jumped in the well, cut their heads, took out hearts, and throws them in the well to please the god. They felt themselves lucky to sacrifice their lives. The geologists and tourism department recovered many skulls, skeletons, huge ornaments from the well, some of which are preserved in the anthropological building in Mexico and some place in USA. The water of the well is highly contaminated.

The Spaniards abandoned this city owing to the non-availability of food grains, vegetables, fruits but the pyramids remain here representing the glory of Maya culture, 